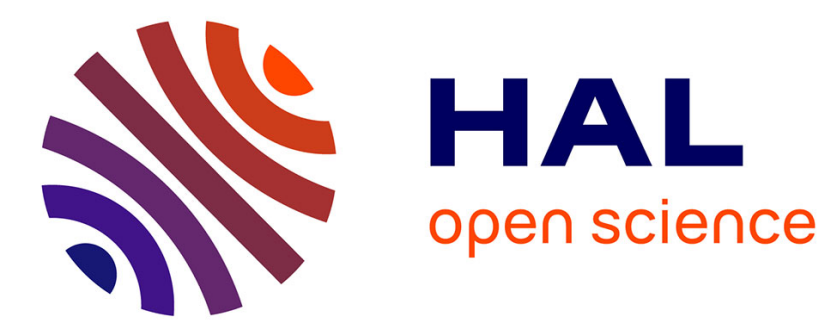

\title{
Stable photorefractive memory effect in sol-gel materials
}

Bruno Darracq, Michael Canva, Frédéric Chaput, Jean-Pierre Boilot, Didier

Riehl, Yves Levy, Alain Brun

\section{To cite this version:}

Bruno Darracq, Michael Canva, Frédéric Chaput, Jean-Pierre Boilot, Didier Riehl, et al.. Stable photorefractive memory effect in sol-gel materials. Applied Physics Letters, 1997, 70 (3), pp.292-294. 10.1063/1.118396 . hal-00668507

\section{HAL Id: hal-00668507 \\ https://hal-iogs.archives-ouvertes.fr/hal-00668507}

Submitted on 9 Feb 2012

HAL is a multi-disciplinary open access archive for the deposit and dissemination of scientific research documents, whether they are published or not. The documents may come from teaching and research institutions in France or abroad, or from public or private research centers.
L'archive ouverte pluridisciplinaire HAL, est destinée au dépôt et à la diffusion de documents scientifiques de niveau recherche, publiés ou non, émanant des établissements d'enseignement et de recherche français ou étrangers, des laboratoires publics ou privés. 


\title{
Stable photorefractive memory effect in sol-gel materials
}

\author{
B. Darracq and M. Canva \\ Groupe d'Optique Non Linéaire, Institut d'Optique Théorique et Appliquée, URA CNRS 14, Bâtiment 503, \\ B.P. 147, 91403 Orsay Cedex, France \\ F. Chaput ${ }^{\mathrm{a})}$ and J.-P. Boilot \\ Groupe de Chimie du Solide, Laboratoire de Physique de la Matière Condensée, URA CNRS 1254 D, \\ Ecole Polytechnique, 91128 Palaiseau, France
}

D. Riehl, Y. Lévy, and A. Brun

Groupe d'Optique Non Linéaire, Institut d'Optique Théorique et Appliquée, URA CNRS 14, Bâtiment 503, B.P. 147, 91403 Orsay Cedex, France

(Received 16 September 1996; accepted for publication 14 November 1996)

\begin{abstract}
We report on the synthesis and the optical characterization of a photorefractive sol-gel material which contains nonlinear azo chromophore and carbazole charge transporting molecules. Both of these functional groups are covalently attached to the silica based backbone. Thin sol-gel films exhibit stable optically nonlinear properties: the electro-optic coefficient $r_{13}$ measured at $633 \mathrm{~nm}$ is found to be $17 \mathrm{pm} / \mathrm{V}$ one day after corona poling and $15 \mathrm{pm} / \mathrm{V}$ after three weeks and over a period of several months. Photorefractivity is demonstrated by two beam coupling experiments without external applied electric field. Sol-gel films present a stable photorefractive memory effect with a net internal gain of $200 \mathrm{~cm}^{-1}$. (C) 1997 American Institute of Physics. [S0003-6951(97)01503-9]
\end{abstract}

Photorefractive materials are of great importance for their potential applications to optical data storage, image processing, and programmable interconnection. ${ }^{1}$ The photorefractive effect can be evidenced from multifunctional materials which combine photosensitivity, photoconductivity, and electro-optic properties. The charge carriers photogenerated in the lighted regions of a spatially modulated illumination migrate by thermal diffusion or electrical drift and become trapped in trapping centers of the dark regions, resulting in the formation of a nonuniform space charge field. The modulation of refractive index is caused, via Pockels effect, by the internal electric field. In the case of two light interfering beams, the photorefractive grating is shifted to the light intensity distribution leading to an asymmetric energy exchange between the two beams. Before 1990, photorefractivity studies were mainly focused on inorganic crystals. ${ }^{2}$ In the early nineties organic materials (single crystals and polymers) emerged as an important new class of photorefractive $\mathrm{media}^{3,4}$ and more recently photorefractivity has been evidenced in hybrid organic-inorganic materials made from the sol-gel process. ${ }^{5,6}$ Sol-gel materials could be efficiently used because of their excellent processability and their high electro-optic coefficients. ${ }^{5}$

In this letter, we report the design, synthesis, and optical characterization of a photorefractive sol-gel material which contains a second order nonlinear chromophore (disperse red one: DR1) and a charge transporting molecule (carbazole unit CB). Both of these functional groups were covalently attached to the silica based backbone thus preventing a phase segregation and crystallization problems. A small amount of 2,4,7-trinitro-9-fluorenone (TNF) was added as a doping molecule to increase the photosensitivity in the visible range. Functionalized silicon alkoxides used to prepare photorefractive sol-gel films are shown in Fig. 1. Detailed synthesis procedures of these precursors were given in a previously

${ }^{a)}$ Electronic mail: fc@pmcsun1.polytechnique.fr published paper. ${ }^{5}$ Coating solutions were obtained from copolymerization of modified silane monomers with tetraethoxysilane (TEOS) (Fig. 1). The composition was Si-DR1:Si-CB:TEOS:TNF= 1:2:0.5:0.0274 (molar ratio). Films of several microns in thickness were elaborated by spin coating on indium tin oxide (ITO) covered substrates and dried at $120{ }^{\circ} \mathrm{C}$ for $5 \mathrm{~min}$. It is then worth noticing that no sample degradation was observed during the months following their preparation. Besides, as shown by the linear absorption spectrum of the composite (Fig. 1), the phase separation process was hindered by the grating of active chromophores.

To induce nonlinear optics (NLO), NLO side groups were oriented in the sol-gel films by single-point corona poling technique (needle-surface distance $=12 \mathrm{~mm}$, voltage $=+5.6 \mathrm{kV}$, poling temperature $=160^{\circ} \mathrm{C}$ ). Electro-optic measurements were performed at $633 \mathrm{~nm}$ on a $3.5-\mu \mathrm{m}$-thick gel film using the ellipsometric method. ${ }^{7}$ The electro-optic coefficient $r_{13}$ was found to be $17 \mathrm{pm} / \mathrm{V}$ one day after corona polling and $15 \mathrm{pm} / \mathrm{V}$ after three weeks, showing a weak relaxation of the nonlinear optical susceptibility.

In order to unambiguously display photorefractivity in our samples, asymmetric two beam coupling (2BC) experiments were performed on the poled sol-gel film without applying an external electric field. A laser beam issued from a continuous wave $\mathrm{He}-\mathrm{Ne}$ laser $(632.8 \mathrm{~nm})$ was divided into two $s$-polarized beams of equal intensity $(2.5 \mathrm{~mW})$. They were superposed onto the sample on the same spot of $1 \mathrm{~mm}$ diameter. The angle between the two beams was $46^{\circ}$ and the grating period of the light interference pattern was equal to $0.81 \mu \mathrm{m}$. The sample was rotated by $+17^{\circ}$ from the axis perpendicular to the bisector direction of the beams. Figure 2(a) presents the normalized intensity $I(t) / I(t=0)$ of both writing beams which was determined from two separate experiments:

(a) In the first one, the normalized transmission of one beam was recorded without the presence of the second 


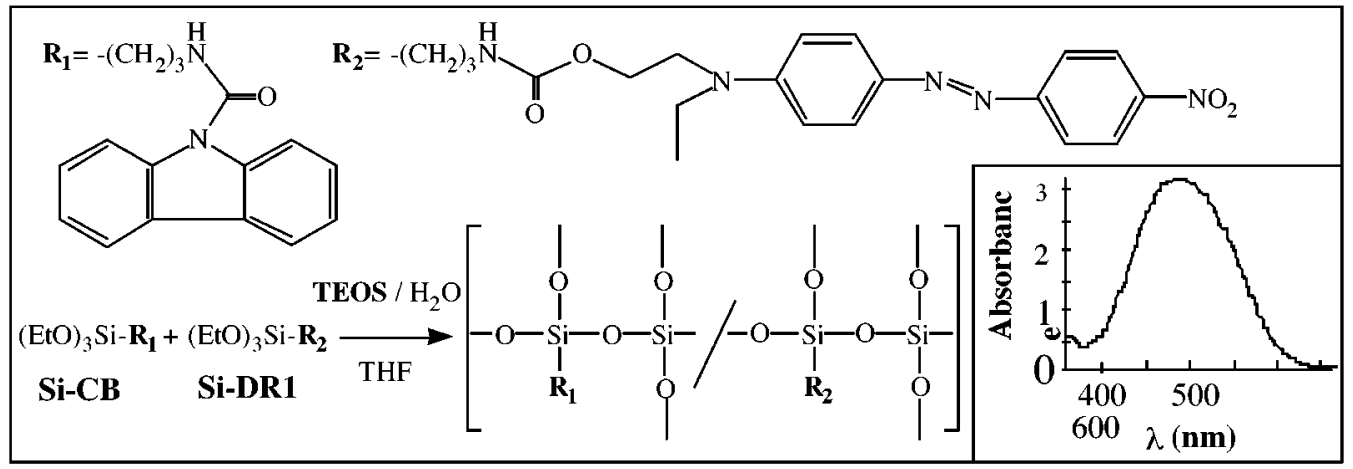

FIG. 1. Chemical structures of the functionalized silicon alkoxides used to prepare photorefractive sol-gel materials. Inset: UV-visible absorption spectra of photorefractive sol-gel film.

one. The fact that the normalized transmission was not constant is due to the photoisomerization of DR1 molecules induced by the weak absorption of the linearly polarized light. ${ }^{8,9}$ As a result, molecules tend to be perpendicularly aligned to the polarization of the writing beams thus leading to a higher transmission of the $s$-polarized light.

(b) In the second experiment, the transmission of beam 1 and beam 2 was recorded for $t=300 \mathrm{~s}$. Then, every 10 $\mathrm{s}$, the two beams were alternatively switched off for $1 \mathrm{~s}$ so that their transmission could be measured. Figure 2(a) exhibits an asymmetric energy exchange which is the clear signature of the photorefractive effect. When the sample was rotated by $180^{\circ}$ around its axis or by $-17^{\circ}$ from the axis perpendicular to bisector direction, we checked that the energy exchange was reversed. This effect was not observed on unpoled samples.

For measuring the energy transfer only due to photorefractive grating, values of $I(t) / I(t=0)$ were divided by the corresponding normalized transmission values for each beam. Figure 2(b) shows the corrected curves which allowed us to measure the asymmetric change of intensity of the writing beam due to the phase shifted photorefractive grating and to determine the $2 \mathrm{BC}$ gain coefficient by the following formula:

$$
\Gamma=[\ln (m \gamma)-\ln (1+m-\gamma)] / L,
$$

where $L$ is the optical path (for beam with gain), $m$ the ratio of the two writing beam energies before crossing the sample ( $m=1$ in our case), and $\gamma$ the beam coupling ratio. The saturation corrected ratio $I(t) / I(t=0)=\gamma=1.08$ of beam 1 leads to a value of $\Gamma$ of about $450 \mathrm{~cm}^{-1}$. This value must be compared to the absorption coefficient $\alpha$ of $560 \mathrm{~cm}^{-1}$ at the same wavelength. So the net internal gain $\Gamma-\alpha$ is negative, which is not favorable for most applications. However, a modification of the optical setup can allow us to reach a positive internal gain as illustrated by the following example. First, the intensity of the amplified beam was divided by 7 so as to be in favorable configuration for a high intensity amplification of the weak beam. Second, the sample was further tilted, $\theta=34^{\circ}$ instead of $\theta=17^{\circ}$, to lead to a stronger effective nonlinear coefficient $\left(r_{\text {eff }}=r_{13} \sin \theta\right)$. With these optical parameters a similar sample exhibited a net internal gain of $200 \mathrm{~cm}^{-1}$.

Erasure time of photorefractive grating was also recorded under uniform illumination by one of the beams while the other was switched off (at $t=320 \mathrm{~s}$ ), then switched on every $60 \mathrm{~s}$ for $1 \mathrm{~s}$ to perform the measurements [Fig. $2(b)]$. Decay time at $90 \%$ of the saturation value was about $350 \mathrm{~s}$. It is important to notice that in dark conditions no decay of the photorefractive grating was observed after a few days.

In order to characterize more accurately the photorefractive behavior of the doped xerogel samples, an external elec-
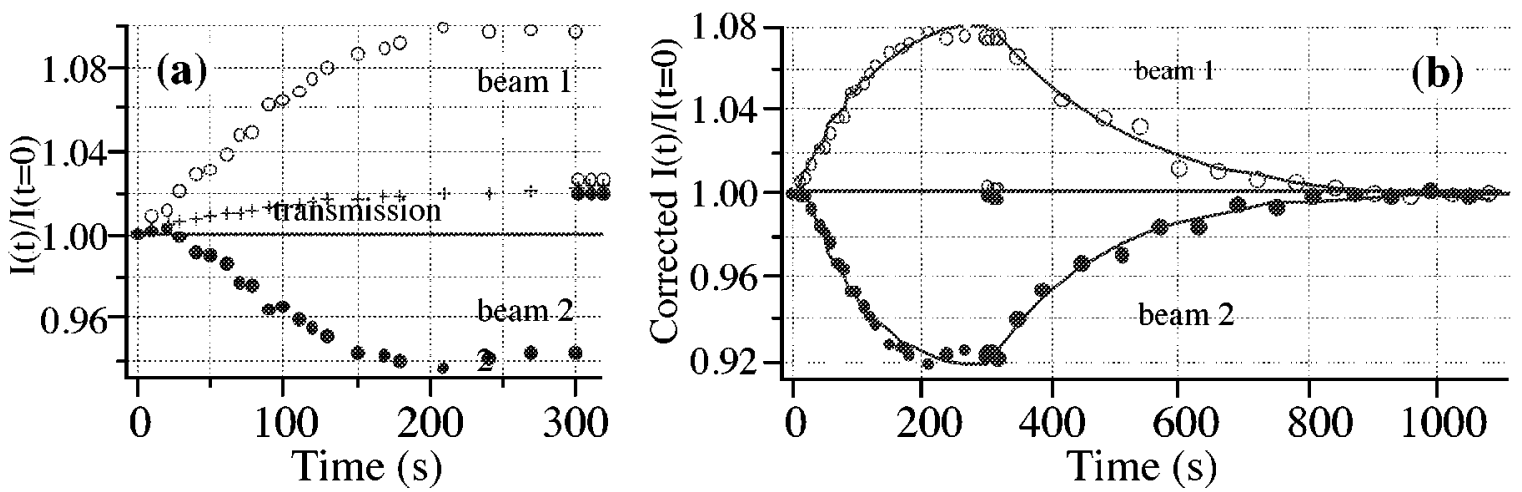

FIG. 2. (a) $2 \mathrm{BC}$ experimental results at $633 \mathrm{~nm}$ for pole sol-gel films (see text for further information). Crosses correspond to the evolution of the normalized transmission for one beam while the other is switched off. (b) Corrected experimental values for 2BC experiments taking into account the change of the transmission for each beam. Optical erasure of the photorefractive grating by one of the writing beams occurs at $t=320 \mathrm{~s}$. Monoexponential fits (dashed lines) are guides for the eyes. Rise and decay times for beam 1 at $90 \%$ of the saturation are respectively 170 and $350 \mathrm{~s}$. 


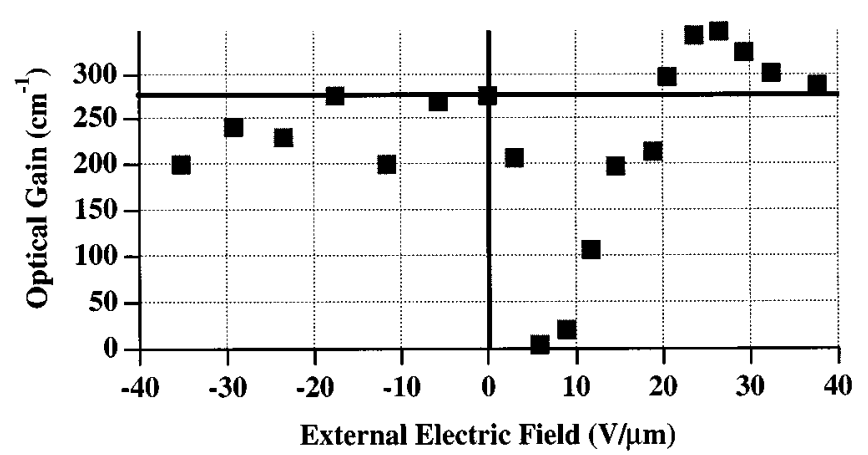

FIG. 3. Photorefractive optical gain evolution as a function of an external applied electric field.

tric field was then applied during the $2 \mathrm{BC}$ experiments. Thus a thin film of gold was deposited on the multilayer structure glass/ITO/photorefractive film allowing to apply a static electric field between the electrodes (ITO/gold). This electric field was made to vary from $-40 \mathrm{~V} / \mu \mathrm{m}$ to $+40 \mathrm{~V} / \mu \mathrm{m}$, the positive sign indicating that the voltage was applied in the same direction as the poling field which was used to orient the nonlinear chromophores. Our experimental result is presented in Fig. 3. Starting from a strong coupling coefficient of $275 \mathrm{~cm}^{-1}$ at zero external field, this coupling coefficient decreased to nearly $0 \mathrm{~cm}^{-1}$ when the field was increased from 0 to about $6 \mathrm{~V} / \mu \mathrm{m}$. For higher field up to $40 \mathrm{~V} / \mu \mathrm{m}$, the coupling coefficient increased and reached a maximum value of about $350 \mathrm{~cm}^{-1}$ then decreased to a saturation value of $275 \mathrm{~cm}^{-1}$ corresponding to the one measured with initial zero applied field. When the sign of the external electric field was reversed, the evolution of the coupling coefficient was completely different: no strong minimum was observed, its value, about $250 \mathrm{~cm}^{-1}$, seemed to be independent of the one of the electric field.

The applied field $6 \mathrm{~V} / \mu \mathrm{m}$ corresponding to the minimum value of the coupling can be interpreted as the external electric field which is required to compensate for the strong internal field which intrinsically exists in the material due to the high orientation and concentration of oriented polar dye molecules.

We may thus explain the photorefractive behavior of the material and the strong coupling coefficient which is observed without applying external electric field: when a free charge (hole) is generated by the absorption of light by a carbazole/TNF complex (the electron is trapped in the TNF structure), it is immediately drifted by the internal electric field which is present in this type of oriented polar material. This prevents the immediate recapture of the free positive charge, enhancing the free carrier generation efficiency.
Comparing this hybrid material to the organic ones, i.e., xerogels vs polymers, one can point out some differences.

(1) The orientation of the NLO dye allows to obtain a material that possesses a very high electro-optic coefficient without external applied electric field.

(2) The rigidity of the doped xerogel is such that the nonlinear properties are stable over a period of several months.

(3) The high level of concentration and orientation of the polar dye used as a NLO source causes a strong internal electric field leading to a high photorefractive response without having to apply any external electric field.

(4) Finally, the material exhibits a stable photorefractive memory effect.

As a conclusion, the photorefractive behavior of sol-gel materials has been demonstrated and it clearly appears that it notably differs from that of their organic polymer counterparts. This was achieved by preparing functionalized precursors with two different chromophores: DR1 molecules, to ensure the second order nonlinear optical response of the material, and carbazole units in order to ensure the charge transport. Dispersed TNF molecules used together with carbazole units give the charge generation. The sol-gel reaction leads to stable optically nonlinear second order thin films. Photorefractivity has been shown by $2 \mathrm{BC}$ experiments without external applied electric field. The presence of an internal electric field appears as essential to interpret the strong observed coupling and the photorefractive behavior.

Different syntheses and experiments are in progress in order to better understand these materials and their photorefractive response, and to optimize their overall promising performances.

${ }^{1}$ Photorefractive materials and their applications I and II, edited by P. Günter and J. P. Huignard (Springer, Berlin, 1989).

${ }^{2}$ Photorefractive materials, MRS Bull. 19, 3 (1994) and references therein.

${ }^{3}$ K. Sutter and P. Günter, J. Opt. Soc. Am. B 7, 2274 (1990).

${ }^{4}$ W. E. Moerner and S. M. Silence, Chem. Rev. 94, 127 (1994); G. G. Malliaras, Ph.D. dissertation, University of Groningen, 1995; K. Meerholz, B. L. Volodin Sandalphon, B. Kippelen, and N. Peyghambarian, Nature 371, 497 (1994).

${ }^{5}$ F. Chaput, D. Riehl, J. P. Boilot, K. Cargnelli, M. Canva, Y. Levy, and A. Brun, Chem. Mater. 8, 312 (1996); B. Lebeau, C. Sanchez, S. Brasselet, J. Zyss, G. Froc, and M. Dumont, New J. Chem. 20, 13 (1996); F. Chaput, B. Darracq, J. P. Boilet, D. Riehl, T. Gacoin, M. Canva, Y. Levy, and A. Brun, Mater. Res. Soc. Symp. Proc. 435, 583 (1996).

${ }^{6}$ R. Burzynski, M. K. Casstevens, Y. Zhang, and S. Ghosal, Opt. Eng. (Bellingham) 35, 443 (1996).

${ }^{7}$ C. C. Teng and H. T. Man, Appl. Phys. Lett. 56, 1734 (1990).

${ }^{8}$ S. Xie, A. Natansohn, and P. Rochon, Chem. Mater. 5, 403 (1993).

${ }^{9}$ F. Chaput, J. P. Boilot, D, Riehl, and Y. Levy, SPIE's International Symposium on Optics, Imaging and Instrumentation, 1994 (unpublished), Vol. 2288, Sol. Gel Optics III, 286 (1994). 